\title{
DRUG UTILIZATION AND PRESCRIBING PATTERN ANALYSIS IN ORTHOPAEDIC OUTPATIENT DEPARTMENT OF TERTIARY CARE HOSPITAL
}

\author{
DHIVYA K*, SHIVA SHANKARI R, MOHAMMED ZULKARNANE A, GAUTAM R
}

Department of Pharmacy Practice, K.K. College of Pharmacy, Chennai. Email: divyapharmd@gmail.com

Received: 17 March 2021, Revised and Accepted: 05 May 2021

\begin{abstract}
Objective: The objective of conducting prescribing pattern study is to monitor, evaluate, and if necessary, recommend modifications in the prescribing behavior of medical practitioners. Hence, this study was conducted to analyze the drug utilization and prescribing pattern of drugs in orthopedic outpatient department (OPD).
\end{abstract}

Methods: This prospective observational study was conducted in the orthopedic OPD of tertiary care hospital for a period of 3 months. Data were obtained from the prescriptions through one-to-one interviews and recorded in a separately designed case report form.

Results: Out of the 260 patients enrolled in the study, 181 were female and 79 were male. The patients between the ages of 50 and 60 years constituted the higher number with a mean age of 52.2 years. The total number of drugs prescribed in the analyzed prescriptions was 1012 which includes orthopedic drugs as well as drugs prescribed to treat various comorbidities. The World Health organization drug prescribing indicators were used to assess the appropriate use of drugs.

Conclusion: Our study concludes that drug utilization and prescribing quality should be improved by promoting medical education on current updates. The periodic audit should be conducted by a clinical pharmacist to reduce an error in the prescription as well as to check the compliance of prescription with standard treatment guidelines for rationalizing the therapy.

Keywords: Orthopedics, Drug utilization, Prescribing pattern, Indicators.

(C) 2021 The Authors. Published by Innovare Academic Sciences Pvt Ltd. This is an open access article under the CC BY license (http://creativecommons.org/ licenses/by/4.0/) DOI: http://dx.doi.org/10.22159/ajpcr.2021v14i6.41474. Journal homepage: https://innovareacademics.in/journals/index.php/ajpcr

\section{INTRODUCTION}

Orthopedics is a branch of medicine broadly concerned with the skeletal system which helps in treating various disorders related to bones, tendons, ligaments, etc. [1]. Various orthopedics problems of old age such as arthritis, osteoporosis, low backache, cervical spondylosis, and radicular pain are referred to as cold orthopedics that are mainly treated by drugs [2]. More than $40 \%$ of patients coming to the outpatient department (OPD) of orthopedics own these cold orthopedics problems. The quality of treatment provided relies on safe and effective therapy at a nominal cost [3]. The prescribing pattern of medicines in orthopedics practice has to be regularly monitored as many of the drugs prescribed carry unwanted adverse effects. The objective of conducting prescribing pattern study is to monitor, evaluate, and if necessary, recommend modifications in the prescribing behavior of medical practitioners to make medical care cost effective and rational [4]. Increased adverse drug reactions and drug pricing have heightened the importance of drug utilization studies. The assessment of drug utilization is important for educational, clinical, and economic purposes [5]. Drug utilization studies help us in finding a new path to implement rational drug therapy as well as to improve the domain of treatment. Drug utilization pattern has to be evaluated periodically to promote rational drug use, enable suitable modifications in prescription to increase the therapeutic benefit and decrease the adverse effects [6]. The World Health organization (WHO) defines rational drug prescribing as using an appropriate drug at the right dose, to the right patient, at correct time intervals for a right duration [7]. To promote rational use of drugs in developing countries, international agencies such as the WHO, International Network for the Rational Use of Drugs, and associations such as World Health Assembly, National Drug Policy, and American Association of Orthopedics have evolved standard drug use indicators and treatment guidelines [8]. The three drug use indicators developed to measure the rational use of drugs are prescribing practices, patient care, and facility-specific factors [9]. Nearly all orthopedics patients are suffering from pain which is an unpleasant feeling that affects daily activities. To overcome that, orthopedist will prescribe predominantly analgesics followed by adjuvant drugs. Hence, this study was conducted to analyze the drug utilization and prescribing pattern of drugs in the orthopedic OPD.

\section{METHODOLOGY}

\section{Study Design and Setting}

This prospective observational study was conducted in the orthopedic OPD of tertiary care hospital for a period of 3 months from December 2017 to February 2018. This study was carried out after obtaining the Institutional Ethics Committee Clearance. The data were collected after obtaining written informed consent from patients. A total of 260 prescriptions were collected from patients above 18 years of age visiting the OPD and willing to participate in the study.

\section{Data Collection}

Data were obtained from the prescriptions through one-to-one interviews and recorded in a separately designed case report form. Data assessed from the prescriptions include demographic profile, allergic status, medical history, medication history, and surgical history. The data were then analyzed using the WHO prescribing indicators such as drugs prescribed by generic or brand name, drugs prescribed in combination with antibiotics, drugs per prescription, those prescribed from the WHO essential medicine list [10].

\section{Statistical Analysis}

The collected data were entered into Microsoft Excel 2013 and analyzed using GraphPad Prism 7.0 software. Data were analyzed using descriptive statistics for the tables of frequency and its associate percentage was calculated. 


\section{RESULTS}

Out of 260 patients enrolled in the study, 181 were female and 79 were male. The patients between the ages of 50 and 60 years constituted the higher number with a mean age of 52.2 years. Age-wise distribution is shown in Fig. 1. The literacy background was poor with illiterates 143 (55\%). The comorbidities commonly observed in our study were hypertension $(25 \%)$, followed by diabetes $(17 \%)$. The comorbiditywise distribution is shown in Fig. 2. The basic demographic details of the study population are shown in Table 1 . Different orthopedic disorders which are seen in our study are shown in Table 2.

The total number of drugs prescribed in the analyzed prescriptions was 1012 which includes orthopedic drugs as well as drugs prescribed to treat various co-morbidities which are shown in Table 3. The frequency of drug administration and the duration of treatment were mentioned in all prescriptions. Drug interactions that are analyzed from the prescribed drugs are shown in Table 4. The WHO drug prescribing indicators are used to assess the appropriate use of drugs is shown in Table 5.

\section{DISCUSSION}

A total of 260 patients were included in the study out of which 79 $(30.3 \%)$ were male and $181(69.7 \%)$ were female with a mean age of 52.2 years which complies with the findings of Kishore et al. study [11]. The major comorbidities found in our study were hypertension (25\%) and diabetes $(17 \%)$ which is similar to Syed et al. study report [12]. Ideally, the prescription should contain fewer number of drugs to prevent the incidence of adverse effects and drug interactions but polypharmacy is the usual practice in the present clinical settings. The average number of drugs per prescription is an important index of the standard of prescribing. The average number of drugs per prescription in our study is 5 which are higher than the WHO guideline, which is alike to the report of Srividya et al. study [13]. NSAIDs and analgesics were more commonly prescribed. Proton pump inhibitors (16.7\%) were more commonly co prescribed with analgesics which is identical to the study performed by

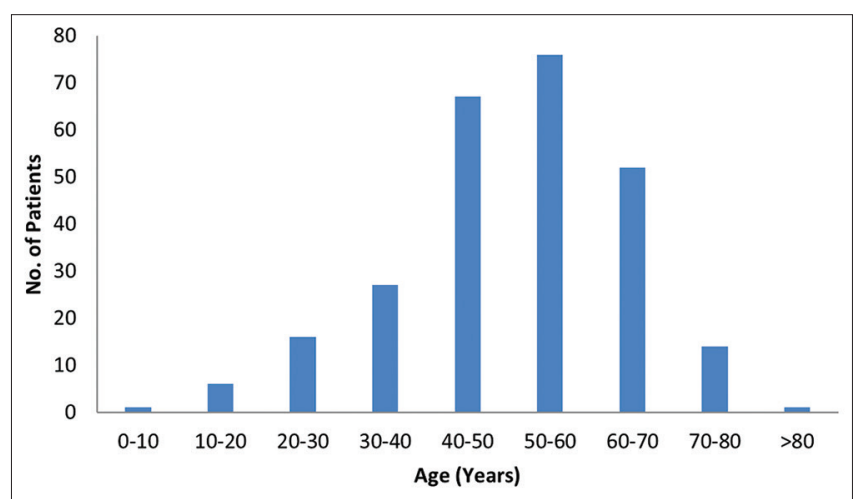

Fig. 1: Age-wise distribution

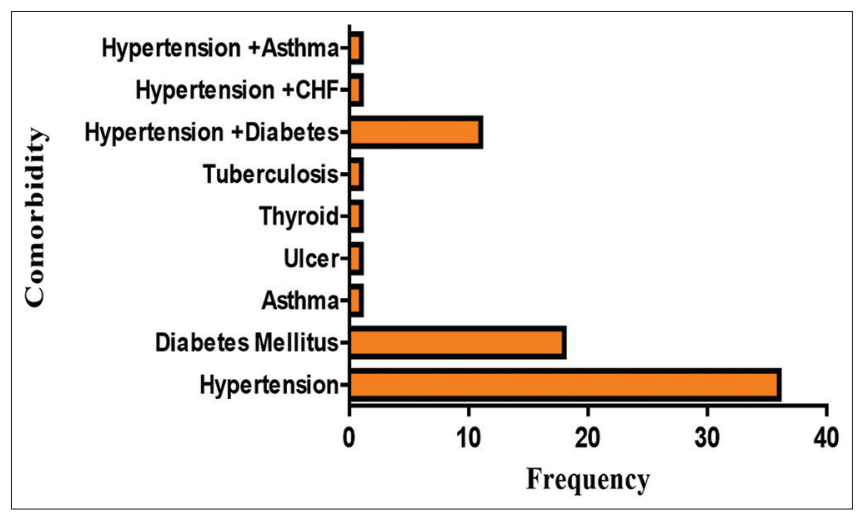

Fig. 2: Comorbidity wise distribution
Shankar et al. [14]. Drugs were not prescribed in their generic name in our study while the WHO guideline- recommended prescribing drugs

Table 1: Basic demographic details of the study population

\begin{tabular}{ll}
\hline Demographic details & Mean \pm SD $/ \mathbf{n}$ (\%) \\
\hline Age (years) & $52.2 \pm 13.46$ \\
Gender & \\
Male & $79(30.3)$ \\
Female & $181(69.7)$ \\
Height $\left(\mathrm{m}^{2}\right)$ & $2.71 \pm 0.167$ \\
Weight $(\mathrm{kg})$ & $55.67 \pm 3.39$ \\
Body mass index $\left(\mathrm{kg} / \mathrm{m}^{2}\right)$ & \\
Underweight $(<18.5)$ & $11(4.24)$ \\
Normal weight $(18.5-25)$ & $247(95)$ \\
Overweight $(25-30)$ & $1(0.38)$ \\
Obese $(>30)$ & $1(0.38)$ \\
Literacy background & $143(55)$ \\
Illiterate & $117(45)$ \\
Literate & $111(42.7)$ \\
Occupational Status & $91(35)$ \\
Housewife & $8(3.07)$ \\
Farmer & $7(2.7)$ \\
Student & $19(7.3)$ \\
Employee & $10(3.85)$ \\
Business & $8(3.07)$ \\
Self-employed & $6(2.31)$ \\
Labor & \\
Retired & $252(96.9)$ \\
Marital status & $8(3.1)$ \\
Married & \\
Unmarried & $19(7.3)$ \\
Food habit & $241(92.7)$ \\
Vegetarian & \\
Mixed & $14(5.4)$ \\
Allergy & $246(94.6)$ \\
Yes & \\
No & $15(5.8)$ \\
Social history & $245(94.2)$ \\
Smokers/Alcoholic & \\
Non-smokers/Non-alcoholic & $25(9.6)$ \\
Substance abuse & $235(90.4)$ \\
Betel-nut and betel leaf & \\
Nil & $68(26)$ \\
Surgical history & $192(74)$ \\
Yes & \\
No & \\
\hline & \\
&
\end{tabular}

Table 2: Distribution of various orthopedic conditions observed in the present study

\begin{tabular}{lll}
\hline Condition & n (260) & \% \\
\hline Osteoarthritis (OA) & 161 & 61.9 \\
Shoulder pain & 5 & 1.9 \\
Foot injury & 12 & 4.6 \\
Wrist injury & 4 & 1.5 \\
Hand injury & 4 & 1.5 \\
Low back ache & 24 & 9.2 \\
Neck pain & 5 & 1.9 \\
Knee injury & 9 & 3.5 \\
Gouty arthritis & 2 & 0.8 \\
Sciatica & 2 & 0.8 \\
Fractures (Tibia, Pubic, Ankle, Ribs) & 8 & 3 \\
Knee pain & 3 & 1.2 \\
Ankle injury & 4 & 1.5 \\
Shoulder injury & 5 & 1.9 \\
Thumb injury & 3 & 1.2 \\
Polyarthralgia & 2 & 0.8 \\
Rheumatoid arthritis & 1 & 0.4 \\
Hip pain & 2 & 0.8 \\
Leg injury & 2 & 0.8 \\
Osteoporosis & 1 & 0.4 \\
Ring finger injury & 1 & 0.4 \\
\hline
\end{tabular}


Table 3: List of drugs prescribed in the study population

\begin{tabular}{|c|c|c|c|c|}
\hline S. No. & Dosage form & Class & Drugs & n (\%) \\
\hline \multirow[t]{18}{*}{1.} & Oral & Analgesics & Lornoxicam + Paracetamol & $161(15.9)$ \\
\hline & & & Etodolac + Paracetamol & \\
\hline & & & Aceclofenac & $45(4.4)$ \\
\hline & & & Diclofenac & $20(1.9)$ \\
\hline & & & Aceclofenac + Paracetamol & $25(2.5)$ \\
\hline & & & Diclofenac + Paracetamol & $10(0.9)$ \\
\hline & & & Aceclofenac + Rabeprazole & $42(4.15)$ \\
\hline & & agents and Anti-ulcerants & Rabeprazole +Domperidone & $74(7.3)$ \\
\hline & & COX-2 inhibitors & Etoricoxib + Thiocholchicide & $59(5.8)$ \\
\hline & & Glucocorticoids & Deflazacort (Deflavab) & 195 (19.3) \\
\hline & & Anti-hypertensives & Enalapril & $1(0.1)$ \\
\hline & & & Atenolol & $12(1.2)$ \\
\hline & & & Metoprolol, Propranolol & $2(0.2)$ \\
\hline & & & Telmisartan & $7(0.7)$ \\
\hline & & Anti-thyroid agents & L-thyroxine & $1(0.1)$ \\
\hline & & Anti-asthmatics & Budesonide & $1(0.1)$ \\
\hline & & Anti-arrhythmics & Aspirin, Clopidogrel, Atorvastatin & $2(0.2)$ \\
\hline & & Others & Calcium carbonate + Calcitriol & $36(3.6)$ \\
\hline \multirow[t]{3}{*}{2} & Parenteral & Corticosteroids & Triamcinolone & $25(2.5)$ \\
\hline & & NSAIDs & Piroxicam & $85(8.4)$ \\
\hline & & Vitamin supplement & Methylcobalamine & $15(1.5)$ \\
\hline 3. & Topical & Analgesic & Diclofenac gel & $88(8.7)$ \\
\hline
\end{tabular}

Table 4: Drug interactions analyzed based on severity (Total=79)

\begin{tabular}{lll}
\hline S. No. & Type of interactions & No of drug interactions \\
\hline 1. & Severe & 8 \\
2. & Moderate & 51 \\
3. & Mild & 20 \\
\hline
\end{tabular}

Table 5: Assessment of the WHO drug prescribing indicators

\begin{tabular}{lll}
\hline S. No. & Prescribing Indicators & n (\%) \\
\hline 1. & Number of drugs per prescription & 5 \\
2. & Drugs prescribed by generic names & $0(0 \%)$ \\
3. & Drugs prescribed in injection dosage form & $125(12.4 \%)$ \\
4. & Drugs prescribed from the essential drug list & $100 \%$ \\
5. & Prescription encounters with antibiotics & $0(\%)$ \\
6. & Average cost per prescription in Indian Rupee & 378 \\
& (INR) & \\
\hline
\end{tabular}

WHO: World Health Organization

by generic names. When compared to branded drugs, generic drugs are cheaper which can be afforded by the patients easily for treatment [15]. Most of the drugs prescribed in the OPD are through oral route whereas parenteral are used more commonly in in-patients. The percentage of parenteral used in OPD is $12.4 \%$ which is less compared to the standard value (13.4-14.1\%) mentioned in the WHO guideline which complies with the findings of Siddaruda et al. study [16]. Overutilization of parenteral products results in increased economic cost as well as the use of non-sterile injections can contribute to the transmission of the virus and other pathogens which leads to health issues such as hepatitis, HIV/AIDS, and other blood-borne diseases. Fixed drug combination (FDC) provides better patient compliance; concomitantly chances for adverse effects are also more. The FDCs observed in the present study were around $40.2 \%$, very high in OPD practice which is dissimilar to the findings of Rajeev et al. study [17]. The average cost per prescription in this study was found to be 378 INR. It increases when patients are admitted to the hospital and also when medicines are required for a longer period [18]. Evaluation of whether drugs are prescribed or not from an essential drug list or national drug formulary serves as one of the indicators to measure rational drug use [19]. In the present study, it was observed that $100 \%$ of prescribed drugs were from the WHO essential drug list. Eight severe drug interactions were found that may result in gastrointestinal toxicity and reduced cardioprotective effect which was analyzed using Micromedex software. Although it was analyzed, not observed in the patients. Hence, it was reported to the physicians to monitor the patients regularly to avoid the occurrence of drug interactions. No significant adverse drug reaction was observed in any patient throughout the study.

\section{CONCLUSION}

Our study concludes that average drugs encountered per patient should be minimized and physicians are requested to prescribe drugs in their generic name only. Drugs that are prescribed to our study population comply with clinical practice guidelines. Drug utilization and prescribing quality should be improved by promoting medical education on current updates to the doctors. Pharmacists should participate actively in updating drug information to the physicians and other health care professionals. A periodic audit should be conducted by a clinical pharmacist to reduce an error in the prescription as well as to check the compliance of prescription with standard treatment guidelines for rationalizing the therapy.

\section{ACKNOWLEDGMENT}

The authors are thankful to the subjects who participated in the study and management for providing excellent research guidance and support.

\section{AUTHORS CONTRIBUTION}

Dhivya participated in the design of study and performed the statistical analysis. All other authors helped to draft the manuscript. All authors read and approved the final manuscript.

\section{CONFLICT OF INTEREST}

The authors have no conflict of interest to declare. We certify that we have no affiliations with or involvement in any organization or entity 
with any financial interest in the subject matter or materials discussed in this manuscript.

\section{REFERENCES}

1. Sharma L. Osteoarthritis year in review 2015: Clinical. Osteoarthritis Cartilage 2016;24:36-48

2. Indranil B, Tania B, Mukesh A. Prescribing pattern in orthopedics outpatient department of a medical college in India. Int J Basic Clin Pharmacol 2015;4:1175-7.

3. Kaur S, Rajgopalan S, Kaur N, Shafiq N, Bhalla A, Pandhi P, et al. Drug utilization study in medical emergency unit of a tertiary care hospital in North India. Emerg Med Int 2014;97:578

4. Kazi AR, Mostafa K, Sanjida A, Tahmina A. Prescribing pattern of NSAIDs in orthopedic department of Dhaka Medical College Hospital. J Dhaka Med Coll 2016;25:58-60.

5. Mohanraj RM, Sreelakshmi N, Padmanabha RY, Anand M. Prescribing patterns of non-steroidal anti-inflammatory drugs (NSAIDS) in outpatient department of an orthopedic specialty hospital. J Glob Trends Pharm Sci 2016;7:3296-301.

6. Seheli SB, Minhazur R, Ahsan U. Drug utilization study in orthopaedic units: Antibiotics prescribed in hospital out-patients in Dhaka, Bangladesh. Int Curr Pharm J 2014;3:318-21

7. Chaturvedi VP, Maj G, Mathur AG, Anand AC. Rational drug use-as common as common sense? Med J Armed Forces India 2012;68:206-8.

8. Ross-Degnan D, Laing R, Quick J, Ali HM, Ofori-Adjei D, Salako L, et al. A strategy for promoting improved pharmaceutical use: The international network for rational use of drugs. Soc Sci Med 1992;35:1329-41.

9. Ubedulla S, Sekhar NC, Jayasree T, Shankar J, Rohit K. Prescription trends in department of orthopedics at tertiary care teaching hospital. J Chem Pharm Res 2013;5:512-7.

10. Richard O, Petra B, Allyson MP. Prescribing indicators at primary health care centers within the WHO African region: A systematic analysis (1995-2015). BMC Public Health 2016;16:724.

11. Kishore P, Prathyusha K, Ramesh K. Prevalence and prescribing pattern in orthopaedic department at a rural hospital set up-a prospective observational study. Eur J Pharm Med Res 2017;4:355-61.

12. Syed IS, Mohamed A, Jayadevan S, Kishore GS. Prescribing patterns in the Orthopedics outpatient department in GMC Hospital, Ajman, United Arab Emirates. Gulf Med Univ Proc 2014;1:120.

13. Srividya BP, Shashikumar NS, Amardeep G. Retrospective audit of prescription of drugs among inpatients of orthopedic wards at Medical CollegeTeaching Hospital, Mandya. Natl J Physiol Pharm Pharmacol 2016;6:282-5

14. Shankar PR, Pai R, Dubey AK, Upadhyay DK. Prescribing patterns in the orthopaedics outpatient department in a teaching hospital in Pokhara, Western Nepal. Kathmandu Univ Med J (KUMJ) 2007;5:16-21.

15. Dilnasheen S, Venkat M, Shamaprakash K. Assessment of medication errors and adherence to WHO prescription writing guidelines in a tertiary care hospital. Future J Pharm Sci 2017;3:60-4

16. Siddaruda MB, Neeraja N, Pathi I, Manjunatha RG, Vijaykumar W, Navanath VK, et al. Prescribing pattern, drug utilization and clinical pharmacy services in orthopaedic patients. Am J Drug Discov Dev 2017;7:63-9.

17. Rajeev D, Prashant W, Hareshwar K, Swati R. Prescription pattern and rationality of drugs study of patients of OPD (outpatient) of orthopedics department of RKDF medical college hospital and Research Centre, Bhopal, MP, India. Int J Basic Clin Pharmacol 2017;6:117-22.

18. Nagla A, Wadagbalkar P, Raipurkar S, Patel P. Prescription pattern study of drugs in orthopedics outpatient department (OPD) of a Rural Medical College Hospital and Research Centre in MP. Int J Orthop Surg 2016;2:367-71

19. Mekonnen S, Getnet M, Bereket M, Firehiwot A, Tesfaye G. Evaluation of rational drug use based on World Health Organization core drug use indicators in selected public hospitals of eastern Ethiopia: A cross sectional study. BMC Ser 2017;17:161 